\title{
Unforeseen Effects of COVID-19 on Adolescent Health
}

\author{
Mishu Mangla $^{1}$ (D)
}

Received: 10 May 2021 / Accepted: 19 August 2021 / Published online: 10 September 2021

(c) Federation of Obstetric \& Gynecological Societies of India 2021

\begin{abstract}
India is presently in the midst of a major health crisis with the second wave of corona virus spreading at an alarming rate and claiming more lives than ever before. Although the pandemic is affecting the lives of all sections of society, adolescent girls being a vulnerable group are affected in dual manner, not just by the direct effects of the virus but also by many still underrated indirect effects. The present article aims to highlight the indirect yet sinister effects of COVID-19 on physical, mental, social, sexual and reproductive and psychological health and well-being of adolescent girls and other issues like their personal safety, peer support and long-term health issues.
\end{abstract}

Keywords adolescent health $\cdot$ COVID-19 . childhood obesity

India is presently in the midst of a major health crisis with the second wave of corona virus spreading at an alarming rate and claiming more lives than ever before. The country now has the second highest number of cases in the world, only after USA, and at the present pace would soon overtake it as well in near future [1]. COVID-19 pandemic has been a major setback to the health and well-being of all sections of the society. Adolescent girls being a vulnerable group are affected in dual manner, not just by the direct effects of the virus but also by many still underrated indirect effects.

Adolescence is a period when major transitions are occurring in the life of females. Apart from bodily changes that mark puberty, hormonal and emotional changes are a hallmark of this period. A number of major decisions like education, career opportunities, time of marriage, etc., are taken during this time period. Adolescent health is probably one of the worst affected with a number of domains including education, physical and mental health, personal safety, sexual and reproductive health, peer support and economic aspects being affected.

Dr. Mishu Mangla is Assistant Professor, Department of Obstetrics \& GynaecologyAll India Institute of Medical Sciences, Bibinagar, Hyderabad.

Mishu Mangla

mishusingla83@gmail.com

1 Department of Obstetrics \& Gynaecology, All India Institute of Medical Sciences, Bibinagar, Hyderabad, India
Isolation, social distancing and avoiding group activities, essential as a measure to prevent the spread of COVID, have had adverse effects on the physical and mental health of adolescent girls [2]. Physical inactivity and unhealthy eating behaviours have been associated with a tremendous increase in childhood and adolescent obesity, more so in urban areas $[3,4]$. Increase in the body mass index would further lead to an increase in gynaecological diseases like polycystic ovarian disease, hirsutism, abnormal uterine bleeding, infertility and also a long-term increased risk of ovarian and endometrial cancers [5]. The long-term effects that this may have in future are yet to be seen and truly estimated.

Mental health of adolescents has also suffered a major setback at the time of pandemic. There are numerous reports of increased anxiety, stress, impaired sleep, post-traumatic stress disorders $[6,7]$ and suicidal tendencies among adolescents and young women. Stress and anxiety can adversely affect the menstrual health of adolescents, through activation of the hypothalamic-pituitary-gonadal (HPG) axis, thereby altering the neuromodulatory cascade that drives gonadotropin-releasing hormone $(\mathrm{GnRH})$ regulation [8]. The consequence is increase in menstrual irregularities, amenorrhea and abnormal uterine bleeding.

School closure has been implemented all over the world as a preventive measure to decrease the spread of corona virus. Adolescent girls on an average spend much more time doing household chores as compared to boys [9, 10], and once they drop out of school, their possibility of going back to school is far lower than boys and would further add on to 
the gender inequality in education. The problem is probably more in rural areas and would eventually lead to a decrease in the literacy rate in females. Ebola outbreak has already shown that an increase in school dropouts has been associated with an increase in teenage pregnancies [11]. This would further transform into increase in pre-eclampsia, preterm delivery, increased rates of caesarean section and other complications as observed in teenage pregnancies [12]. A low literacy rate has been found to be a strong predictor of anaemia [13], eclampsia and many other obstetric complications. The coming future is thus expected to see many such complications, an indirect and probably unanticipated effect of the current pandemic.

The problems that adolescent girls face in rural areas are multifaceted and largely under-reported. Globally, 1 in 5 girls are married before the age of 18 years, and India alone accounts for one-third of the total cases. It was assumed that the economic destitution, lack of education and communication, poverty and social insecurity would reverse the 25 -year progress in the field of stopping child marriage [17]. Child marriage not only closes the educational and career opportunities that adolescent girls need for economic independence but also translates into increase in teenage pregnancies and their consequent harmful health effects. Strong regulations for preventing sexual- and gender-related violence and childhood marriages are probably required and need to be implemented in an effective manner.

Use of contraception is essential in fertility regulation. Many countries all over the world have done a complete shutdown of transport to and from their boundaries due to lockdown, as a means to control the spread of corona virus. Sexual and reproductive health services have suffered a major setback as these are not considered life-saving. Shortage of all forms of contraceptive methods, especially barrier method, is a major concern. Apart from an increase in unwanted pregnancies, this could lead to an increase in the incidence of HIV (human immunodeficiency virus) and other sexually transmitted diseases [18]. The problem is further confounded by travel restrictions, non-availability of transport services, shutting down of small and primary health clinics and also bigger hospitals being converted into care centres predominantly of COVID patients. Adolescents and young females are unable to access reproductive health services. An increase in unsafe abortions and consequent increase in maternal mortality could be inevitable consequence.

Adolescent health predominantly sexual and reproductive health often takes a backseat and is neglected in health emergency situations [14]. Economic insecurities in pandemics especially that involve quarantine measures have seen an associated sharp increase in gender-based violence in the form of intimate partner violence, rape and domestic violence [15]. A number of countries all over the world have reported a significant increase in violence against women and girls [16], during the course of pandemic, although for majority of underdeveloped countries the exact data might not be available. These have long-term effects on the adolescent health in the form of psychiatric disorders, social and cultural insecurities and suicidal tendencies.

Preventive services too are not spared by the brunt. Vaccination services predominantly against human papilloma virus have shown a sharp decline to the tune of up to $70 \%$ [19]. Vaccination against rubella and flu has also taken a backseat in current scenario. Preventive services like screening for sexually transmitted diseases, iron folic acid supplementation programs, midday meals in schools and regular antenatal check-ups are among the few to be mentioned and are also affected to a great deal. To what extent, all these would translate into increase in anaemia, malnutrition, pregnancy complications and increased incidence of cervical cancer, only the future can tell.

Adolescent health services are a basis to building a strong platform for the well-being of women in reproductive years. Community participation, public awareness campaigns, social protection programs and educational programs mainly focussing on physical and mental health of adolescents are the need of the hour. Prohibition of child marriage and gender-based violence should be prioritised and made an essential and life-saving service. Community workers like ASHAs and auxiliary nurse midwives should be made a part of preventive services like distribution of iron/folic acid tablets and contraceptives in adolescents and also with minimal training be made competent to administer vaccines like HPV, rubella and flu at home. If adolescent health issues are not addressed at this time, the impact that COVID-19 would have on adolescent health would really take a long time to reverse.

Supplementary Information The online version contains supplementary material available at https://doi.org/10.1007/s13224-021-01555-1.

\section{Declarations}

Conflict of Interest The Author declares no conflict of interest.

\section{References}

1. Bhuyan A. Experts criticise India's complacency over COVID-19. Lancet. 2021;397(10285):1611-2.

2. Ammar A, Brach M, Trabelsi K, Chtourou H, Boukhris O, Masmoudi L, Bouaziz B, Bentlage E, How D, Ahmed M, Müller P, Müller N, Aloui A, Hammouda O, Paineiras-Domingos LL, Braakman-Jansen A, Wrede C, Bastoni S, Pernambuco CS, Mataruna L, Taheri M, Irandoust K, Khacharem A, Bragazzi NL, Chamari K, Glenn JM, Bott NT, Gargouri F, Chaari L, Batatia H, Ali GM, Abdelkarim O, Jarraya M, Abed KE, Souissi N, Van 
Gemert-Pijnen L, Riemann BL, Riemann L, Moalla W, GómezRaja J, Epstein M, Sanderman R, Schulz SV, Jerg A, Al-Horani R, Mansi T, Jmail M, Barbosa F, Ferreira-Santos F, Šimunič B, Pišot R, Gaggioli A, Bailey SJ, Steinacker JM, Driss T, Hoekelmann A. Effects of COVID-19 home confinement on eating behaviour and physical activity: results of the eclb-covid19 international online survey. Nutrients. 2020;12(6):1583. https://doi.org/10.3390/nu120 61583.PMID:32481594;PMCID:PMC7352706.

3. Rundle AG, Park Y, Herbstman JB, Kinsey EW, Wang YC. COVID-19-related school closings and risk of weight gain among children. Obesity Silver Spring. 2020;28(6):1008-9.

4. Browne NT, Snethen JA, Greenberg CS, Frenn M, Kilanowski JF, Gance-Cleveland B, Burke PJ, Lewandowski L. When pandemics collide: the impact of covid-19 on childhood obesity. J Pediatr Nurs. 2020. https://doi.org/10.1016/j.pedn.2020.11.004.

5. Kalliala I, Markozannes G, Gunter MJ, Paraskevaidis E, Gabra H, Mitra A, Terzidou V, Bennett P, Martin-Hirsch P, Tsilidis KK, Kyrgiou M. Obesity and gynaecological and obstetric conditions: umbrella review of the literature. BMJ. 2017. https://doi.org/10. 1136/bmj.j4511.PMID:29074629.

6. Guessoum SB, Lachal J, Radjack R, Carretier E, Minassian S, Benoit L, Moro MR. Adolescent psychiatric disorders during the COVID-19 pandemic and lockdown. Psychiatry Res. 2020. https:// doi.org/10.1016/j.psychres.2020.113264.

7. Zhang Y, Zhang H, Ma X, Di Q. Mental health problems during the covid-19 pandemics and the mitigation effects of exercise: a longitudinal study of college students in China. Int J Environ Res Public Health. 2020;17(10):3722. https://doi.org/10.3390/ijerp h17103722.PMID:32466163;PMCID:PMC7277113.

8. Williams NI, Berga SL, Cameron JL. Synergism between psychosocial and metabolic stressors: impact on reproductive function in cynomolgus monkeys. Am J Physiol Endocrinol Metab. 2007;293(1):E270-6. https://doi.org/10.1152/ajpendo.00108. 2007.

9. Burzynska K, Contreras G. Gendered effects of school closures during the COVID-19 pandemic. Lancet. 2020. https://doi.org/10. 1016/S0140-6736(20)31377-5.

10. UNICEF. Girls spend 160 million more hours than boys doing household chores everyday. Oct 7, 2016. https://www.unicef.org/ pressreleases/girls-spend-160-million-more-hoursboys-doinghousehold-chores-everyday (accessed April 10, 2020)

11. Elston JWT, Cartwright C, Ndumbi P, Wright J. The health impact of the 2015 Ebola outbreak. Public Health. 2017;143:60-70.

12. Abebe AM, Fitie GW, Jember DA, Reda MM, Wake GE. Teenage pregnancy and its adverse obstetric and perinatal outcomes at Lemlem Karl Hospital, Tigray, Ethiopia, 2018. Biomed Res Int. 2020;19(2020):3124847. https://doi.org/10.1155/2020/3124847. PMID:32051825;PMCID:PMC6995314.

13. Mekonnen FA, Ambaw YA, Neri GT. Socio-economic determinants of anemia in pregnancy in North Shoa Zone, Ethiopia. PLoS ONE. 2018. https://doi.org/10.1371/journal.pone.0202734.
14. Jennings L, George AS, Jacobs T, Blanchet K, Singh NS. A forgotten group during humanitarian crises: a systematic review of sexual and reproductive health interventions for young people including adolescents in humanitarian settings. Confl Health. 2019;13(1):15-7.

15. John N, Casey SE, Carino G, McGovern T. Lessons Never Learned: Crisis and gender-based violence. Dev World Bioeth. 2020;20(2):65-8.

16. Policy Brief: The Impact of COVID-19 on Women. United Nations. [cited 2021 Apr 9]. Available from https://unsdg.un. org/ resources/policy-brief-impact-covid-19-women

17. Cousins S. $2 \cdot 5$ million more child marriages due to COVID-19 pandemic. Lancet. 2020;396(10257):1059. https://doi.org/10. 1016/S0140-6736(20)32112-7.

18. Goga A, Bekker LG, Van de Perre P, El-Sadr W, Ahmed K, Malahleha M, Ramraj T, Ramokolo V, Magasana V, Gray G. Centring adolescent girls and young women in the HIV and COVID19 responses. Lancet. 2020;396(10266):1864-6.

19. Hoffman J, Vaccine rates drop dangerously as parents avoid doctor's visits, New York Times, Apr. 23, 2020, https://www.nytim es.com/2020/04/23/health/coronavirusmeasles-vaccines.html.

Publisher's Note Springer Nature remains neutral with regard to jurisdictional claims in published maps and institutional affiliations.

\section{About the Author}

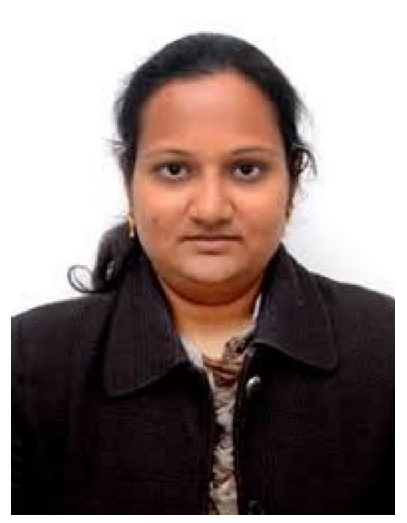

Mishu Mangla is Assistant Professor in the Department of Obstetrics and Gynaecology, All India Institute of Medical Sciences, Bibinagar, Hyderabad. She did her post-graduation from the prestigious Sawai Man Singh Medical College, Jaipur. Due to special interest in foetal medicine, she completed Post-Doctoral Certificate Course (PDCC) in Maternal \& Foetal Medicine from AIIMS Rishikesh in 2019. She has presented papers and posters in various national and international conferences and won awards for the same. She has keen interest in academic research of clinical significance. 